\title{
Correction to: Management of chronic ischemic heart disease into internal medicine and geriatric departments in Italy
}

\author{
Francesco Perticone ${ }^{1} \cdot$ Andrea Fontanella $^{2} \cdot$ Nicola Ferrara $^{3} \cdot$ Alberto Ferrari $^{4}$
}

Published online: 28 February 2020

(c) Società Italiana di Medicina Interna (SIMI) 2020

\section{Correction to: \\ Internal and Emergency Medicine (2020) 15:151-154 \\ https://doi.org/10.1007/s11739-019-02197-y}

In the original publication of the article, in the tenth paragraph the sentence that reads as "In addition, heart failure ..... by $66.8 \%$ of the physicians" should read as "The correct line should be read as, In addition, heart failure ..... by $76.8 \%$ of the physicians".

Publisher's Note Springer Nature remains neutral with regard to jurisdictional claims in published maps and institutional affiliations.

The original article can be found online at https://doi.org/10.1007/ s11739-019-02197-y.

Francesco Perticone perticone@unicz.it

1 Italian Society of Internal Medicine (SIMI), Rome, Italy

2 Federazione Delle Associazioni dei Dirigenti Ospedalieri Internisti (FADOI), Rome, Italy

3 Società Italiana di Geriatria e Gerontologia (SIGG), Florence, Italy

4 Società Italiana dei Geriatri Ospedalieri e del Territorio (SIGOT), Rome, Italy 